\title{
Application of potential accessibility models in decision-making on HSR routing: the case of Rapid Connections in Czechia
}

\author{
Jakub Randák ${ }^{1,2, *}$, Miroslav Marada², Miroslav Vrtiška ${ }^{3}$ \\ 1 České dráhy a.s., Czech national carrier, Czechia \\ 2 Charles University, Faculty of Science, Department of Social Geography and Regional Development, Czechia \\ ${ }^{3}$ Czech University of Life Sciences Prague, Faculty of Environmental Sciences, Czechia \\ * Corresponding author: jakubrandak@gmail.com
}

\begin{abstract}
The aim of this article is to discuss regional impacts of high-speed railways on transportation accessibility. It investigates the potential changes in the transportation accessibility of Czech municipalities due to the planned construction of high-speed rail lines in Czechia. It considers two currently discussed variants of the high-speed rail line between Prague and Brno. We discuss the model of potential transportation accessibility and discuss its usability in the preparation and construction of high-speed rail line structures, and how it would affect the optimal route selection. We also present different methods of accessibility analyses in GIS applied to the case of Czechia and their presentation through map outputs.
\end{abstract}

\section{KEYWORDS}

high-speed railway; Czechia; regional and local impacts; potential accessibility

Received: 11 May 2020

Accepted: 2 March 2021

Published online: 17 March 2021

Randák, J., Marada, M., Vrtiška, M. (2021): Application of potential accessibility models in decision-making on HSR routing: the case of Rapid Connections in Czechia. AUC Geographica 56(1), 108-119

https://doi.org/10.14712/23361980.2021.5

(C) 2021 The Authors. This is an open-access article distributed under the terms of the Creative Commons Attribution License (http://creativecommons.org/licenses/by/4.0). 


\section{Introduction}

Transport accessibility is considered one of the basic conditions for the development of a region's economy and also demonstrates the quality of the region's involvement in the labor market (Sands 1993; Gutiérrez 2001 or Chen, Hall 2012). The quality of transport accessibility is also irreplaceable in performing other activities of human life, such as commuting to health care, education, and cultural institutions, but it also plays a role in the development of tourism, etc. "Transport accessibility, along with population density, affects the efficiency of serving the territory and the population" (Maier et al. 2007: 6).

In an elementary manner, transport accessibility can be understood as the ease or difficulty of reaching a place or service from other places. Accessibility can be expressed in terms of the distance traveled or the travel costs or travel time expended (Clark 1990). It can be "defined as the ease of reaching a certain location in space" (Giuliano 1995 in Hudeček et al. 2011: $1)$. It is in transport geography that one can most often encounter the expression of transport accessibility based on the time needed to cover a given distance. The term accessibility usually refers to the concept of a proximity of two points in space, to the simplicity of spatial interactions, or to the potential of contacts with different types of services and functions (Michniak 2002). Accessibility, however, can also be understood as a chance to enable a person occupying a certain space to utilize different types of activities (Taylor 1997), i.e. "the potential of opportunities for interaction in space" (Hansen 1959 in Hudeček et al. 2011: 1).

Moreover, in transport geography, great attention is paid to the study of accessibility as one of the key concepts. Today, the most frequently monitored are accessibilities from peripheral areas to core areas, whether by public or individual transport. Due to the fact that transport accessibility is one of the most significant manifestations of changes in the transport network, the concept of accessibility is used to express changes in the territory that will be caused by the construction of new transport roads.

Given that accessibility is an issue affecting different fields (transport, spatial planning, marketing, etc.), it does not necessarily always work with only a temporal dimension. GIS integrated tools have also brought new opportunities for study. In addition to time accessibility, for example, cumulative accessibility is also analyzed, which is expressed as the number of certain activities attainable from a particular location at a particular time. An example would be the number of jobs available per hour of driving from the municipality of residence (ESPON TRACC project). Accessibility may therefore include not only spatial dimensions but also social or economic dimensions such as population size, unemployment rate, etc. (Salze et al.
2011). While a simple expression of temporal accessibility involves only the aspect of distance and cumulative accessibility distance and a certain activity, both expressions lack the aspect of the center's location relative to others and do not take into account their differentiated meaning. Equally large headquarters located at the same distance from Brno or from Karlovy Vary will have differentiated position potential due to differences in the importance of Brno, respectively Karlovy Vary. This problem involves the concept of potential accessibility, which is essentially a derivative of the gravitational model.

The potential as an index of geographical availability has been used in geography for quite some time (Rich 1980). Originally, population potential was understood as a measure of a geographical change in the vicinity of all or part of a country's population. Later, this concept was extended to reflect the proximity of job opportunities, the availability of services, etc. (Guy 1983).

Basic services such as shops, banks, post offices, medical facilities, but also job opportunities are less easily accessible from rural or peripheral areas than in large cities. Thus, some people may be twice disadvantaged - they do not have a sufficient choice of services or employment opportunities, and they live far from the desired service (Haynes et al. 2003). It is with regard to the attractiveness of the services in question that we cannot only consider the temporal dimension in such a case. That is why we include the potential of the service or job opportunities in the transport accessibility research.

Another example might be to find an answer to the question "What is the accessibility of a particular business to a potential employee?" (Van Wee et al. 2001: 3). Generally, it can be assumed that only people with certain temporal accessibility (e.g. 30 minutes) will be included as potential employees of the company. However, given that we cannot only consider the temporal dimension of commuting, but also the attractiveness of a given job opportunity or regional unemployment rate, it is necessary to include these in the form of the weight of centers in the accessibility calculations. In this case, we also work with the so-called potential accessibility. Similarly when assessing alternative solutions to transport systems (e.g. different routing of rail connections), it is important not only to consider the aspect of time accessibility but also to consider potential accessibility, which will comprehensively assess the location of settlements in the newly proposed infrastructure.

This paper aims to present the advantages of potential accessibility models use in decision-making on routing the high-speed rails. We will demonstrate the model's use on the case of Czech HSR plans called the Rapid Connections and will assessed two variants of tracing between Prague and Brno by potential accessibility concept. 


\section{A tool for modeling potential accessibility: network dataset and parameters of network analysis}

The key source of the GIS accessibility model is, besides the timetable, a sufficiently accurate map background.

\subsection{Creation the network dataset in GIS}

The model is characterized by a GIS network data set (NDS) of digital vector data representing the transport network (in this case the railways) and containing, apart from the lines and nodes, also adequately selected attributes. These are average train speed and hence the time needed to cover the given distance. These attributes will ultimately enable the specific software to find, for example, the shortest path or to construct isochrons (e.g. Hudeček et al. 2011) by a gradual cumulation of the travel time between the individual inter-nodal sections. The weight of the nodes could be added as well, e.g. population size, number of jobs available, and other. Final created Network Dataset (NDS) contains all railway line's sections needed and their junctions (centroids of settlements connected to stations and stops, ends of tracks or sections, and their crossings). The advantage of time-demanding creating the NDS is its variability for different destinations - once an accessibility model is compiled it can then be used to analyze the accessibility of any point in the network (or multiple points at once).

In the model used in this research, all rail tracks in operation were included and future HSR track were digitalized according to current plans of Ministry of Transportation of Czechia. Each section of the railway line has the specific time needed to pass the section either by local train (Os in Czech terminology) or by express train (R) or by higher quality train (IC/EC) calculated in the attribute table. The time required to pass a given section represents the fastest possible connection in the train in the categories mentioned according to the timetable. Speeds of the planned HSR sections were taken from strategic materials of the Ministry of Transport of the Czech Republic. The times of transfers between individual lines and the time of train stay at the station are not consider in this analysis. It would not even be useful to include the time of transfer between individual trains in the calculations, as this may change with a change in train transport concept or with the positioning of individual trains within the timetable.

Then, the ArcGIS tool, the Network Analyst with Python SW extension, was used for calculation time and potential accessibility. The time accessibility was expressed between each pair of stations/municipalities in the regional model and between the fast-train stations in the long-distance model. So, each network section was given the time spent on the train.

The resulting time distances, in this case, are therefore partly theoretical, even though the speed has been optimized on the basis of a real timetable. The difference between theoretical and real-time can be explained by the following effects: the vectorized railway network is slightly generalized, the accessibility model does not allow for waiting at the station, and the speed was primarily determined by the typology of the tracks and later adjusted to the timetable. Although the distortion is minimal with regard to the national level of assessment, it is therefore important to consider model distortion when interpreting the results. The time calculated from the model may be slightly lower than real-time, however, this detail is sufficient for the purpose of expressing the changes caused by the construction of HSR.

\subsection{Calculation of potential accessibility}

To calculate the potential accessibility of all municipalities in Czechia served by rail transport on the basis of the population, the authors' script was used. Potential accessibility $A_{i}$ for specified point layers with $i$ (origins) and $j$ (destinations) was expressed according to the formula:

$$
A_{i}=\sum_{j} \text { Weight }_{j}^{\alpha} \times \exp \left(-\beta \times \text { TravelTime }_{i, j}\right),
$$

where Weight ${ }_{j}^{\alpha}$ determines the importance (weight) of locality $j$, here it represents the population, coefficient $\alpha$ adjusts the weight of the centers (not considered in this case), TravelTime ${ }_{i, j}$ represents the travel time (time accessibility) between nodes $i$ and $j$ and the coefficient $\beta$ is an argument of the exponential function, which is used here as the distance impedance (resistance). The value $\beta$ determines how strict the weight reduction of the centers will be with respect to the time distance (see below).

Specifically, the following inputs were used to calculate potential accessibility:

1) Origins - this is a point layer of municipalities in Czechia from the ArcČR 500 geodatabase version 2.0 by ARCDATA Praha, s. r. o., to which we count the potential accessibility. Abput concerning the fact that there is no railway line to each municipality in Czechia, only the municipalities served by the railway were selected.

2) Destinations - this is the same layer with "origins", so potential accessibility is calculated for each municipality in the context of accessibility to all other municipalities in Czechia served by rail.

3) Network - the layer of the railway network. It consists of (i) the layer of stop trains with all the railway stops and the travel time of the stop trains and (ii) the layer of express connections, which contains only train stations of an IC and higher quality trains and future HSR trains. 
4) Impedance - this is an attribute of the transport network; this is an exponential function of a travel time.

5) Weight - this is an attribute of the Origin/Destinations layer, in this case the population was of the municipality used.

The output of the analysis is a new attribute (in the attribute table of the point layer), which represents the value of the potential accessibility, expressed according to the formula above. This value was used for the subsequent visualization of this phenomenon in maps.

For the actual calculation of potential accessibility, determining the value of $\beta$, which affects the proportion of the municipality's population in our case is absolutely crucial. The value of the $\beta$ parameter is selected with concerning for to the selected accessibility model (long-distance, regional) and is determined according to the following formula:

$$
\beta=-\frac{\ln \left(f\left(\text { TravelTime }_{i, j}\right)\right)}{\text { TravelTime }_{i, j}} .
$$

The main way to calibrate the model is to determine the so-called median time value (or: halftime). From the model supplemented data of the 2011 Population and Housing Census on the daily commute to work, it was empirically proven that half of the commuters in Czechia travel to work within 22.5 minutes, half more than 22.5 minutes. This means that we are looking for an exponential function that, for a travel time value of 22.5 minutes, would give such distant centers the weight of just one-half. This corresponds to a coefficient of $\beta=0.030809$. The exponential function in this form assigns a weight of three quarters at a time distance of 9.3 minutes and a weight
Tab. 1 Determination of the $B$ parameter for individual values of "halftime".

\begin{tabular}{|c|c|c|c|c|}
\hline \multirow{2}{*}{$\begin{array}{l}\text { Halftime } \\
\text { value } \\
\text { TravelTime }_{i, j} \\
\text { (minutes) }^{\text {i }}\end{array}$} & \multirow{2}{*}{$\begin{array}{c}\boldsymbol{\beta} \\
\text { parameter }\end{array}$} & \multicolumn{3}{|c|}{$\begin{array}{c}\text { TravelTime }{ }_{i, j} \text { (minutes) } \\
\text { when } f\left(c_{i j}\right) \text { corresponds to }\end{array}$} \\
\hline & & 0.75 & 0.25 & 0.1 \\
\hline 5 & 0.138629 & 2.1 & 10.0 & 16.6 \\
\hline 10 & 0.069315 & 4.2 & 20.0 & 33.2 \\
\hline 15 & 0.046210 & 6.2 & 30.0 & 49.8 \\
\hline 20 & 0.034657 & 8.3 & 40.0 & 66.4 \\
\hline 30 & 0.023105 & 12.5 & 60.0 & 99.7 \\
\hline 45 & 0.015403 & 18.7 & 90.0 & 149.5 \\
\hline 60 & 0.011552 & 24.9 & 120.0 & 199.3 \\
\hline
\end{tabular}

Source: Spiekerman (2012)

Note: From table 1 for the value of the median time ("halftime") 30 minutes, it follows that destinations exactly 30 minutes travel time apart from each other will be weighted at $50 \%$ of their value and correspond to a value of $\beta=0.0223105$. Using this value of the $\beta$ parameter will mean that targets 12.5 minutes from that point will be weighted at $75 \%$ of their value and targets 99.7 minutes will be weighted at only $10 \%$ of their value.

of one-tenth $(10 \%)$ at a distance of 74.7 minutes. These values can be considered as corresponding to reality (Marada et al. 2016). As this model case only deals with rail accessibility and train passengers are generally less sensitive to commuting time than car passengers, the halftime was rounded to 30 minutes for the regional model. Basically, points that will be within 30 minutes traveling from the origin municipality will be counted by their weight value more than the municipalities that are located at a time distance of more than 30 minutes within the network. This calculation, therefore, takes into account the fact that people travel shorter distances more than longer distances. In the case of a long-distance model, we applied analogously the halftime of 60 minutes. This

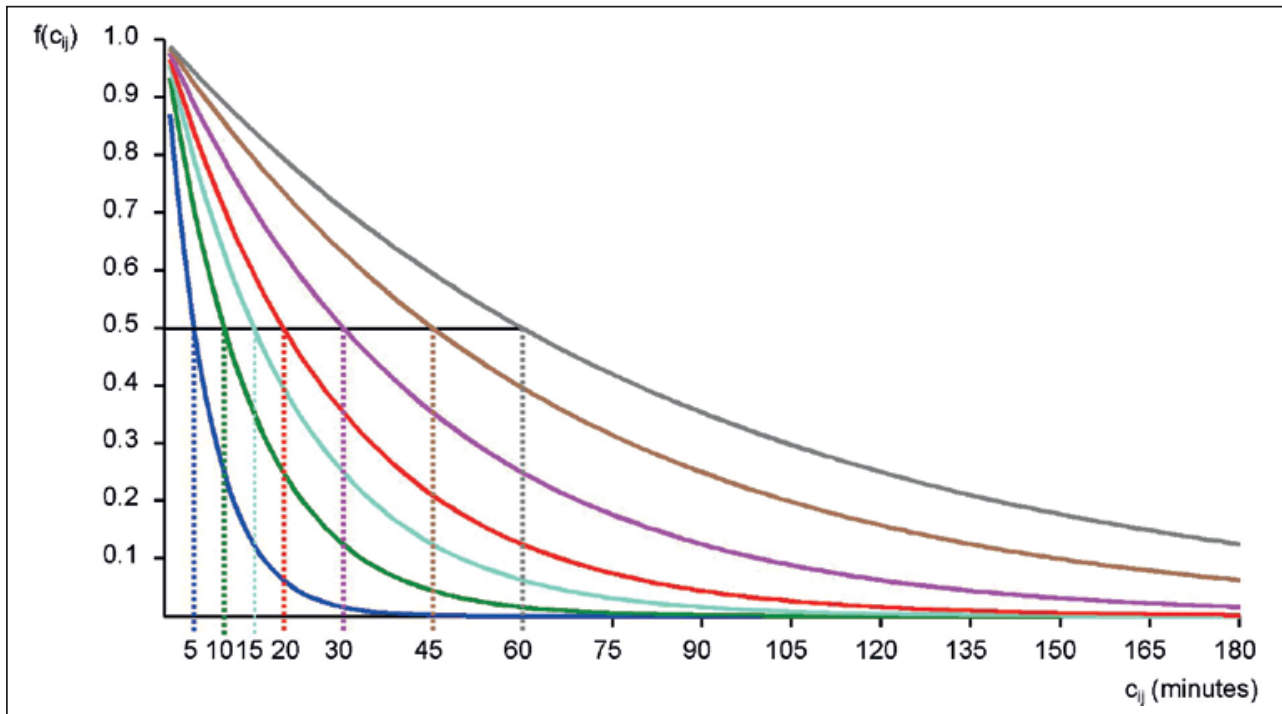

Fig. 1 Weight curves for each accessibility model.

Source: Spiekerman (2012)

Note: The model in this article uses a median time (halftime) of 30 and 60 minutes. 
value was determined with regard to the distance of the regional town of Jihlava as a city with significant potential for daily commuting to Prague and Brno (approx. 45-60 minutes from Prague or Brno). Specific values of travel time, in which the resistance is three quarters (0.75), a quarter (0.25), or one-tenth, are given in Tab. 1 . The $\beta$-values used in regional and long-distance models are tinted. The graph in Fig. 1 below shows the resulting weight curves for 7 different halftime values, respectively values of $\beta$.

\subsection{Variants of planned HSR under consideration}

The case study was used for the routing of the highspeed rail called Rapid Connections in the Czech Republic (see e.g. https://www.szdc.cz/vrt/co-jevrt/postup-pripravy-vrt). The two compared variants were the routing of the Rapid Connection 1 (RS1) in the Central Bohemian Region and the Vysočina Region (see Fig. 2). The RS 1 line will connect the two major cities of Czechia, Prague and Brno. To evaluate the advantages and disadvantages of the individual variants in a complex way, a method of comparing potential accessibility in both variants seems to be suitable.
The potential accessibility models were used to monitor the potential accessibility for three variants the current state of the railway network respecting the almost completed network of transit railway corridors (maximum speed $160 \mathrm{~km} / \mathrm{h}$ ), furthermore, the state after the construction of the HSR with the RS1 line routing variant in the south direction (direction Benešov - Vlašim) and lastly the state after the construction of the HSR with the RS1 line routing variant in the east direction (direction Kolín - Havlíčkův Brod). Furthermore, two model variants were created for each of the three network variants based on a different concept of transport service. The first model always considered the so-called regional system of territorial service with a median time (halftime) of 30 minutes of train running. And the second model considered the so-called long-distance system of territorial service with a median time distance of 60 minutes of train running. Compared to the "classical" time accessibility calculations, the results of these analyzes present the mutual potential accessibility of all municipalities within the whole railway network, and therefore it is not only about accessibility to the capital city or vice versa.

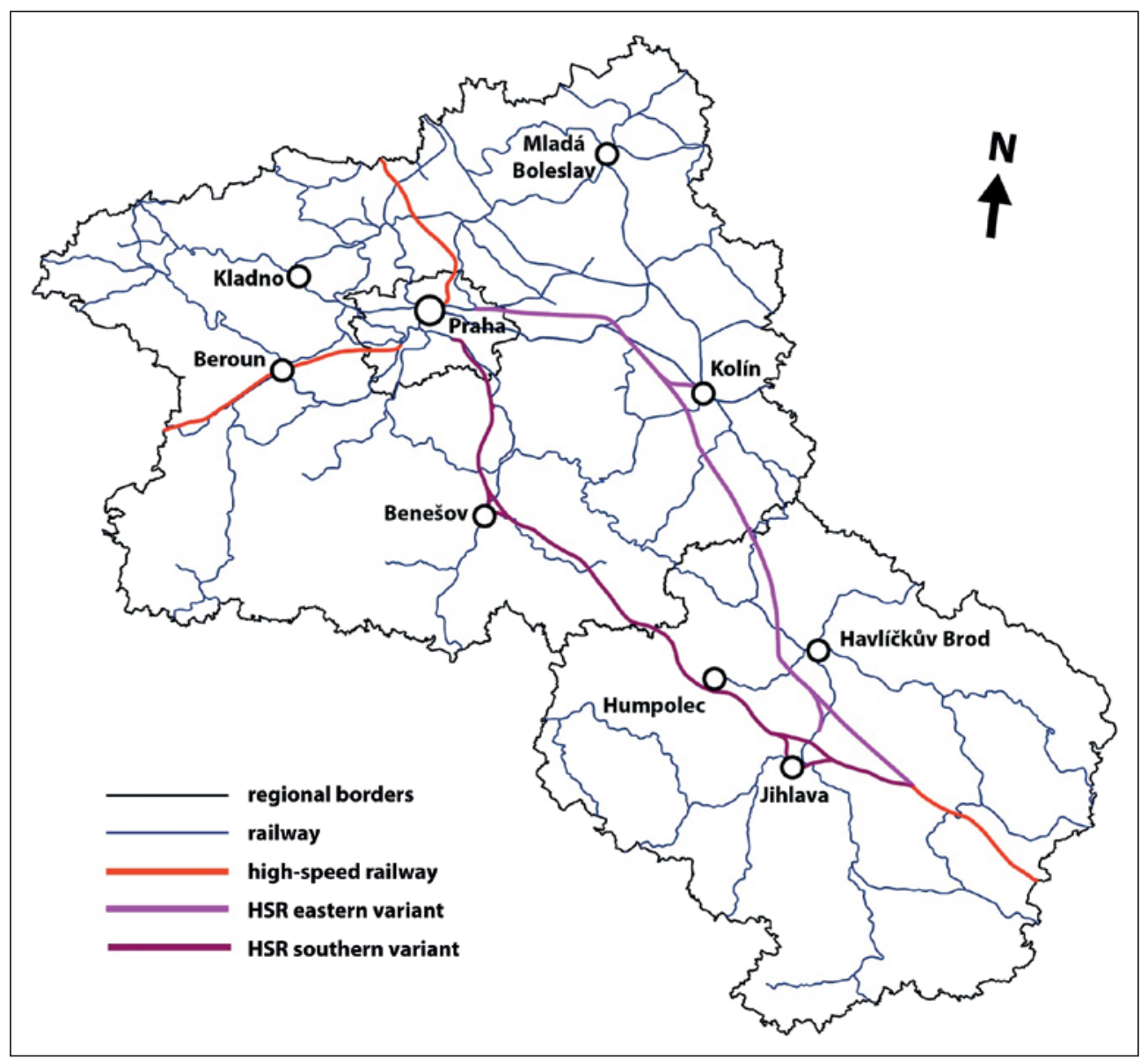

Fig. 2 HSR variant routing in the Central Bohemian Region and Vysočina Region. 
It should be pointed out that the potential accessibility values in the calculations take values in the order of ten million, so for the presentation in the tables, all results are divided by 1,000. For visualization in maps, relativization is used with the average value of potential accessibility per municipality in the null variant (current state, without HSR). This value is always stated in absolute terms in the map notes. The same average value of "null variant" was used as a $100 \%$ value for all other maps for comparability of individual analyzes. Indexes are used to compare different models. Since the calculations of potential accessibility are directly linked to specific points located on the transport network (in this case the railway), these are no results for the whole of Czechia, but only for municipalities with a railway station or stop.

\section{Changes in potential accessibility after the construction of high-speed rail in Czechia}

Potential accessibility analyzes were created for various types of area service, as well as for two different HSR routes in Czechia.

\subsection{Potential accessibility of municipalities in Czechia by rail at present ("null variant")}

Figure 3 illustrates the results of the potential accessibility model currently (2015), which considers the so-called regional transport model. The $100 \%$ value
Tab. 2 Value of potential accessibility of regional cities and its change.

\begin{tabular}{|l|c|c|c|}
\multirow{2}{*}{ City } & \multicolumn{2}{|c|}{ Potential accessibility } & Potential \\
\cline { 2 - 4 } & regional model & $\begin{array}{c}\text { long-distance } \\
\text { model }\end{array}$ & \\
\hline Prague & $82,124.23$ & $82,849.16$ & $+0.87 \%$ \\
\hline Pilsen & $81,312.67$ & $82,384.74$ & $1.32 \%$ \\
\hline Karlovy Vary & $78,540.41$ & $80,992.00$ & $+3.12 \%$ \\
\hline České Budějovice & $78,550.65$ & $81,141.20$ & $+3.30 \%$ \\
\hline Ústí nad Labem & $80,501.89$ & $82,030.83$ & $+1.89 \%$ \\
\hline Liberec & $79,492.65$ & $81,357.02$ & $+2.35 \%$ \\
\hline Hradec Králové & $80,591.91$ & $82,011.54$ & $+1.76 \%$ \\
\hline Pardubice & $81,051.36$ & $82,269.64$ & $+1.50 \%$ \\
\hline Jihlava & $79,396.74$ & $81,404.25$ & $+2.58 \%$ \\
\hline Brno & $80,878.07$ & $82,298.58$ & $+1.75 \%$ \\
\hline Zlín & $79,363.48$ & $81,475.80$ & $+2.66 \%$ \\
\hline Olomouc & $79,629.44$ & $81,438.17$ & $+2.27 \%$ \\
\hline Ostrava & $79,188.89$ & $80,312.55$ & $+1.41 \%$ \\
\hline
\end{tabular}

Source: accessibility analysis, authors' calculation

used to visualize the results is the average potential accessibility of all municipalities - 80,354.

It is clear from Figure 3 that, in the case of the regional model, the highest values of the potential accessibility of the municipality are reached in Prague and its hinterland. The high values of potential accessibility of Prague in all models are due to its relatively central location within the transport network. Municipalities in the hinterland of Prague then logically achieve higher values of potential

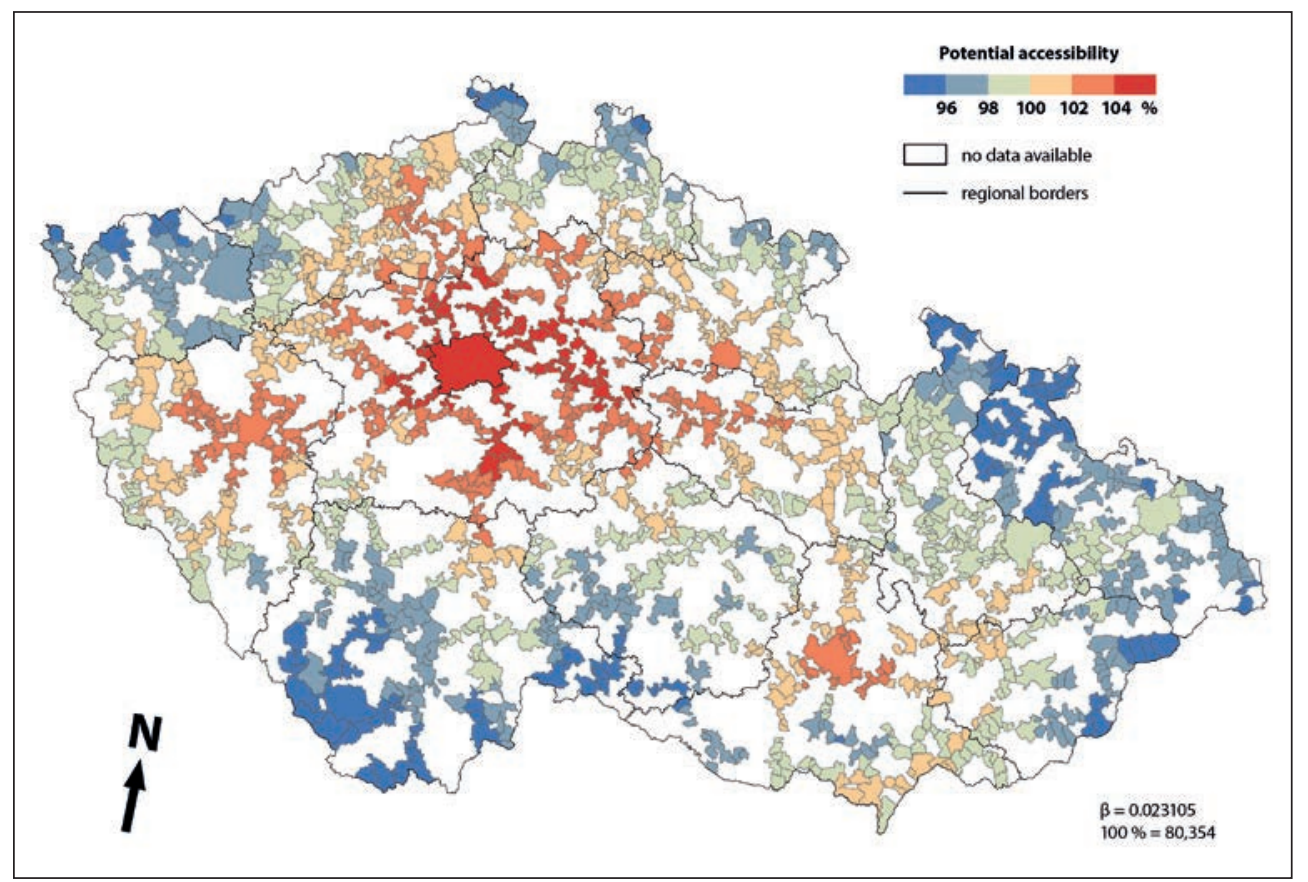

Fig. 3 Potential accessibility of municipalities in Czechia in 2015 (regional model). Source: accessibility analysis, authors' calculation 


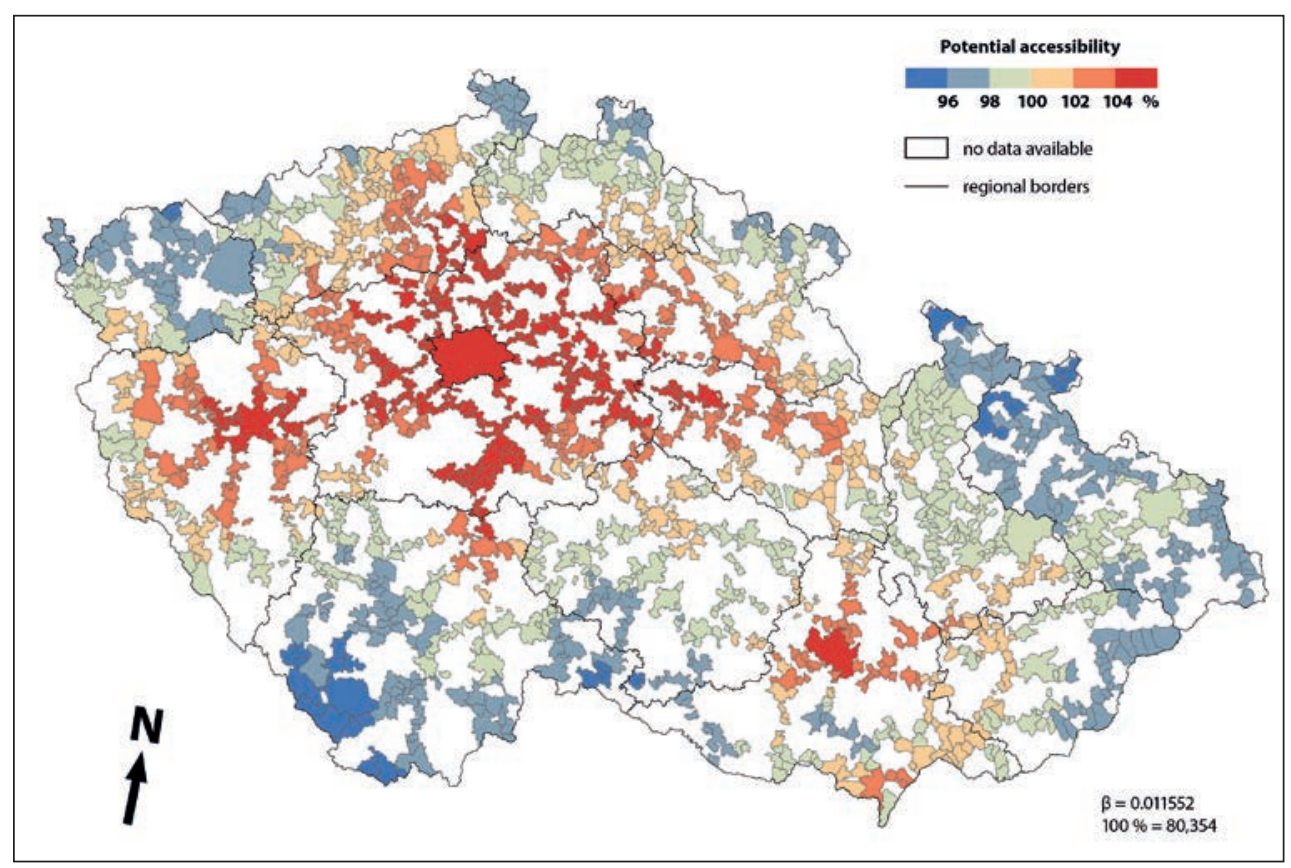

Fig. 4 Potential accessibility of municipalities in Czechia in 2015 (long-distance model).

Source: accessibility analysis, authors' calculation

accessibility precisely because of the high population size of Prague, but also because of their geographical proximity to the capital. These results also correlate to the fact that shorter-distance passengers travel more than longer-distance passengers, respectively the desire to travel decreases over time.

Figure 4 illustrates the results of the potential accessibility model at present (similar to Figure 2) but considers the so-called long-distance accessibility model. This model allows for faster long-distance transport - municipalities (or railway stations) with 60 minutes accessibility are then calculated at a value of $50 \%$ of their population size.

This model suggests that in the case of faster long-distance transport, the attractiveness of municipalities at a greater distance from Prague - the extensive areas of the north-east of the Central Bohemian Region, but also the Benešov Region - will increase. In terms of its location in the transport network and its population size also Pilsen and the municipalities in its hinterland are improved. We can observe the strengthening of the integration of the metropolitan areas in the northern "half" of Bohemia and the integration of the metropolitan area of Brno. An interesting phenomenon is that the potential accessibility of Ostrava is practically unchanged - this is mainly because it is, in terms of the Czech railway network, in a significantly eccentric position in relation to other large cities in Czechia.

Table 2 above and the cartograms (see Figures 3 and 4) show that in the case of the long-distance model, the change in potential accessibility will be most apparent in České Budějovice and Karlovy Vary, as a result of reaching the population-large Prague. The least change in potential accessibility will be seen in the case of Prague, as it benefits from its central location in all surveyed models. This comparison of the regional and long-distance model clearly shows the essential contribution of the fast transit to the interconnection of settlement centers with the Prague core.

\subsection{Potential accessibility of municipalities in Czechia after the construction of HSR - regional model}

The results from the regional models of potential accessibility after completion of the HSR in the eastern and southern RS1 variants are illustrated in Figures 5 and 6 . The $100 \%$ value used in the visualization of relativized values is again the average potential of all municipalities from "null variant" because of the uniformity of maps' comparison.

In the case of the regional model, which in terms of population size most takes into account municipalities within 30 minutes of time accessibility, the municipalities northeast of Prague will gain the most in the case of the eastern variant of RS1, but also the relatively important area of the west of the Pardubice Region and the southern part of the Hradec Králové Region. The potential accessibility of Pilsen will change significantly, which in both variants will obtains a high quality and fast connection with Prague, whose existence will be reflected in the regional model.

If the regional model is applied to the railway network including the RS 1 in the southern variant, then, compared to the eastern variant, the Czech Siberia region (the boundary of the Central Bohemia and 


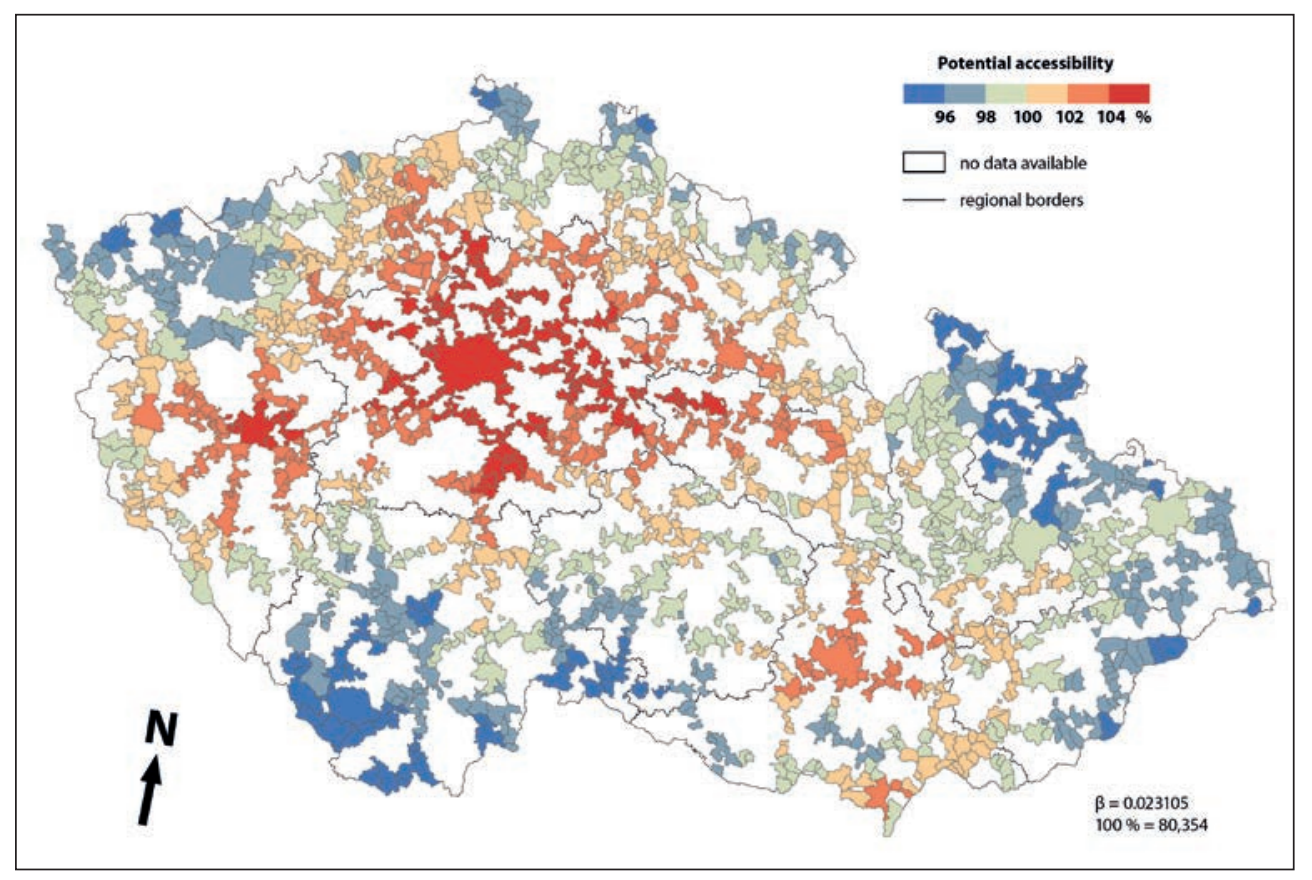

Fig. 5 Potential accessibility of municipalities in Czechia after the construction of HSR in the eastern variant (regional model). Source: accessibility analysis, authors' calculation

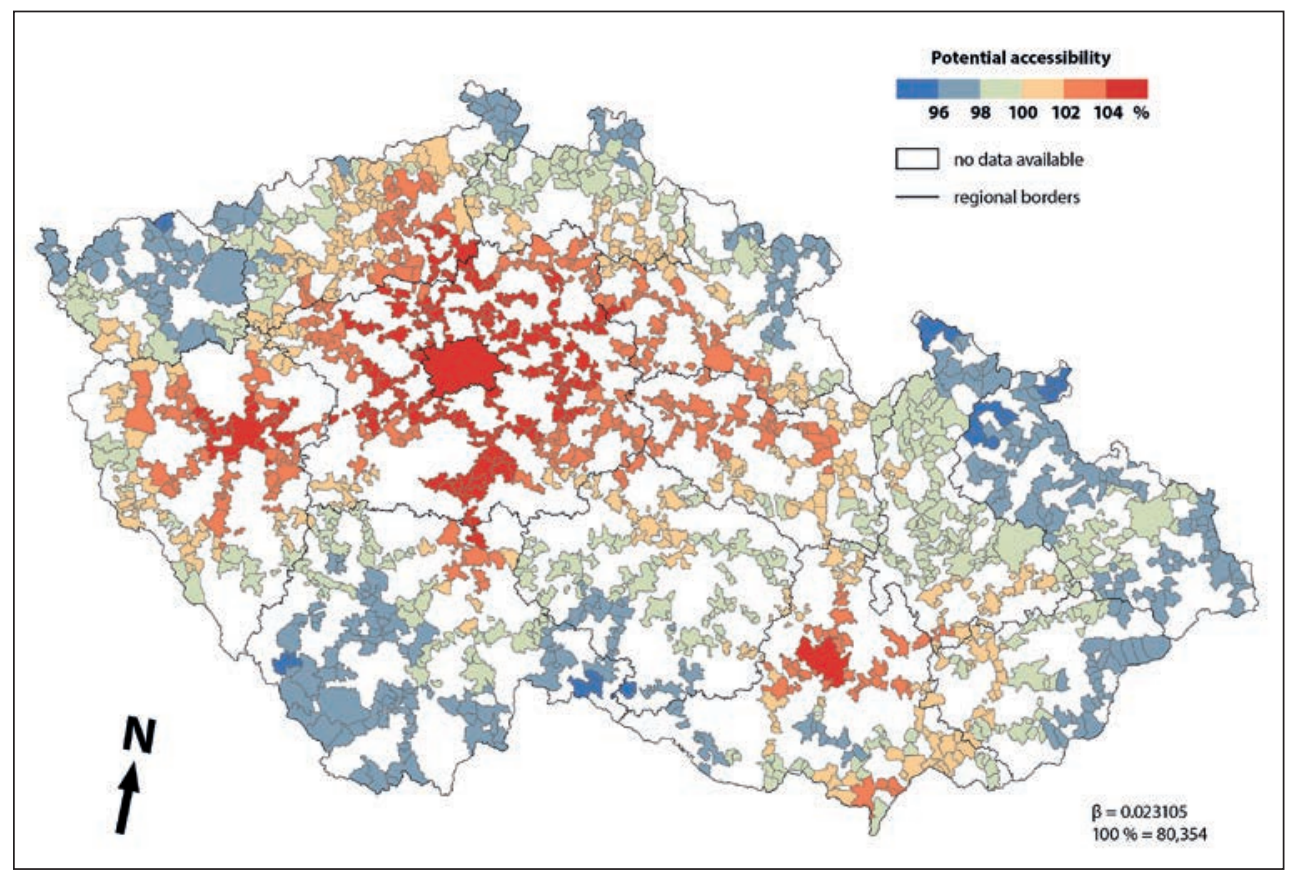

Fig. 6 Potential accessibility of municipalities in Czechia after the construction of HSR in the southern variant (regional model). Source: accessibility analysis, authors' calculation

South Bohemia regions, the so-called inner periphery) has the greatest gains in the potential accessibility. The southern part of the South Bohemia region has little gains in the potential accessibility as well. In this variant, there will be no significant increase in the potential accessibility in municipalities in East Bohemia.

Table 3 below clearly shows changes in potential accessibility for all regional cities in Czechia. In the case of the eastern variant of RS 1 , there is the greatest change in the potential accessibility in the cities of Pardubice and Hradec Králové and, of course, also in the cities currently less accessible - Zlín and Jihlava. In the case of the southern variant of RS 1 , the change will be most apparent in České Budějovice, as well as in the eastern variant near Zlín and Jihlava. The regional model of the service is best recorded in the eastern variant of Karlovy Vary and in the southern variant by České Budějovice. 
Tab. 3 The value of the potential accessibility of regional cities and its change (regional model).

\begin{tabular}{|c|c|c|c|c|c|}
\hline City & $\begin{array}{l}\text { Potential } \\
\text { accessibility - } \\
\text { regional model (null } \\
\text { variant) }\end{array}$ & $\begin{array}{c}\text { Potential } \\
\text { accessibility - } \\
\text { regional model (RS1 } \\
\text { eastern variant) }\end{array}$ & $\begin{array}{l}\text { Change of } \\
\text { potential } \\
\text { eastern/null }\end{array}$ & $\begin{array}{l}\text { Potential } \\
\text { accessibility - } \\
\text { regional model (RS1 } \\
\text { southern option) }\end{array}$ & $\begin{array}{c}\text { Change of } \\
\text { potential } \\
\text { southern/null }\end{array}$ \\
\hline Prague & $82,124.23$ & $82,741.12$ & $+0.75 \%$ & $82,738.11$ & $+0.74 \%$ \\
\hline Pilsen & $81,312.67$ & $82,411.54$ & $+1.35 \%$ & $82,359.90$ & $+1.28 \%$ \\
\hline Karlovy Vary & $78,540.41$ & $79,926.00$ & $+1.76 \%$ & $79,123.55$ & $+0.74 \%$ \\
\hline České Budějovice & $78,550.65$ & $79,441.17$ & $+1.13 \%$ & $80,562.72$ & $+2,56 \%$ \\
\hline Ústí nad Labem & $80,501.89$ & $81,110.88$ & $+0.75 \%$ & $81,024.12$ & $+0,64 \%$ \\
\hline Liberec & $79,492.65$ & $80,377.82$ & $+1.11 \%$ & $80,564.45$ & $+1.11 \%$ \\
\hline Hradec Králové & $80,591.91$ & $82,618.24$ & $+2.51 \%$ & $81,788.13$ & $+1.48 \%$ \\
\hline Pardubice & $81,051.36$ & $82,599.24$ & $+1.90 \%$ & $82,034.11$ & $+1.21 \%$ \\
\hline Jihlava & $79,396.74$ & $81,704.26$ & $+2.90 \%$ & $81,653.87$ & $+2.84 \%$ \\
\hline Brno & $80,878.07$ & $82,235.98$ & $+1.67 \%$ & $82,171.99$ & $+1.59 \%$ \\
\hline Zlín & $79,363.48$ & $81,485.12$ & $+2.67 \%$ & $81,451.92$ & $+2.63 \%$ \\
\hline Olomouc & $79,629.44$ & $81,338.15$ & $+2.14 \%$ & $81,293.51$ & $+2,09 \%$ \\
\hline Ostrava & $79,188.89$ & $80,362.62$ & $+1.48 \%$ & $80,259.18$ & $+1.35 \%$ \\
\hline
\end{tabular}

Source: accessibility analysis, authors' calculation

The total change in the potential for all assessed municipalities in the case of the eastern variant is from $132,855,112.81$ to $134,967,575.21$, which means an increase of potential by $1.59 \%$. In the case of the southern variant, the change from $132,855,112.81$ to $134,249,520.78$ means a potential increase of $1.05 \%$. From point of view of total change, the potential accessibility, the eastern routing of RS 1 appears to be a more advantageous option when applying the regional model, which increases accessibility within the traditional settlement core in the northern "half" of Bohemia. But a fast connection should be the main goal of building HSR, although it will serve for combine service with regional trains. And a regional improvement of accessibility should be the substantial criterion, not an overall one. This view provides the long-distance model in the following chapter.

\subsection{Potential accessibility of municipalities in Czechia after the construction of the HSR - long-distance model}

The results from the models of potential accessibility after completion of the HSR in the eastern and southern RS1 variants, which are considered by the so-called long-distance transport model, are illustrated in Figures 7 and 8.

In the case of the long-distance model, which in terms of population size takes more into account the municipalities within 60 minutes of time accessibility, in the case of the eastern variant of RS1, municipalities northeast of Prague will gain the most, but also a relatively important area of the west of the Pardubice Region and the southern part of the Hradec Králové Region. The potential accessibility of Pilsen will change significantly, due to a high quality and fast connection with Prague again. There will also be a significant increase in the potential accessibility of Brno and municipalities in its hinterland, while the potential of municipalities in the South Bohemian Region will decrease significantly.

If the long-distance model is applied to the railway network including the RS 1 in the southern variant, then, against the eastern variant, the greatest gains in the potential accessibility have the Central Bohemian-South-Bohemian border region and the southern parts of the South Bohemian Region. The potential accessibility of Pilsen will also increase, and the potential accessibility in Brno's hinterland will increase. In this variant, there will be no significant increase in the potential accessibility in municipalities in East Bohemia.

Table 4 below allows see the changes in potential accessibility more precisely. In the case of the eastern variant of RS1 as well as in the regional model, the greatest change in the potential accessibility in the towns of Pardubice and Hradec Králové and of course also in the regional cities currently less accessible Zlín and Jihlava. In the case of the southern variant of RS 1, the change will be most apparent in České Budějovice, as well as in the eastern variant near Zlín and Jihlava. The long-distance model records most in the eastern variant of Hradec Králové, which will thus become more easily accessible from the regions of South Moravia, in the southern variant of České Budějovice, as their accessibility from the whole Czech Republic will improve.

The total change in the potential for all assessed municipalities in the case of the eastern variant is from $135,515,582.28$ to $138,054,138.04$, which 


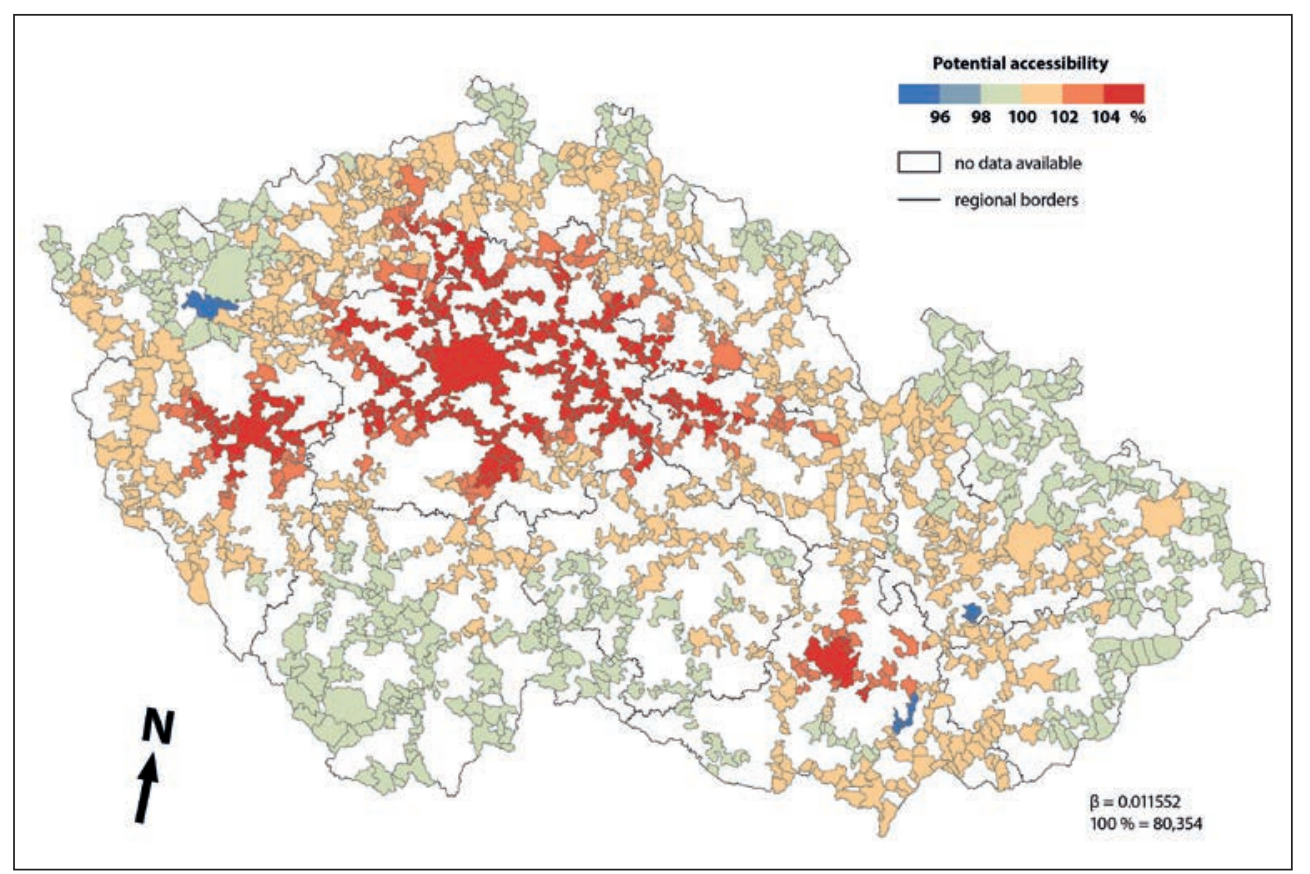

Fig. 7 Potential accessibility of municipalities in Czechia after the construction of HSR in the eastern variant (long-distance model). Source: accessibility analysis, authors' calculation

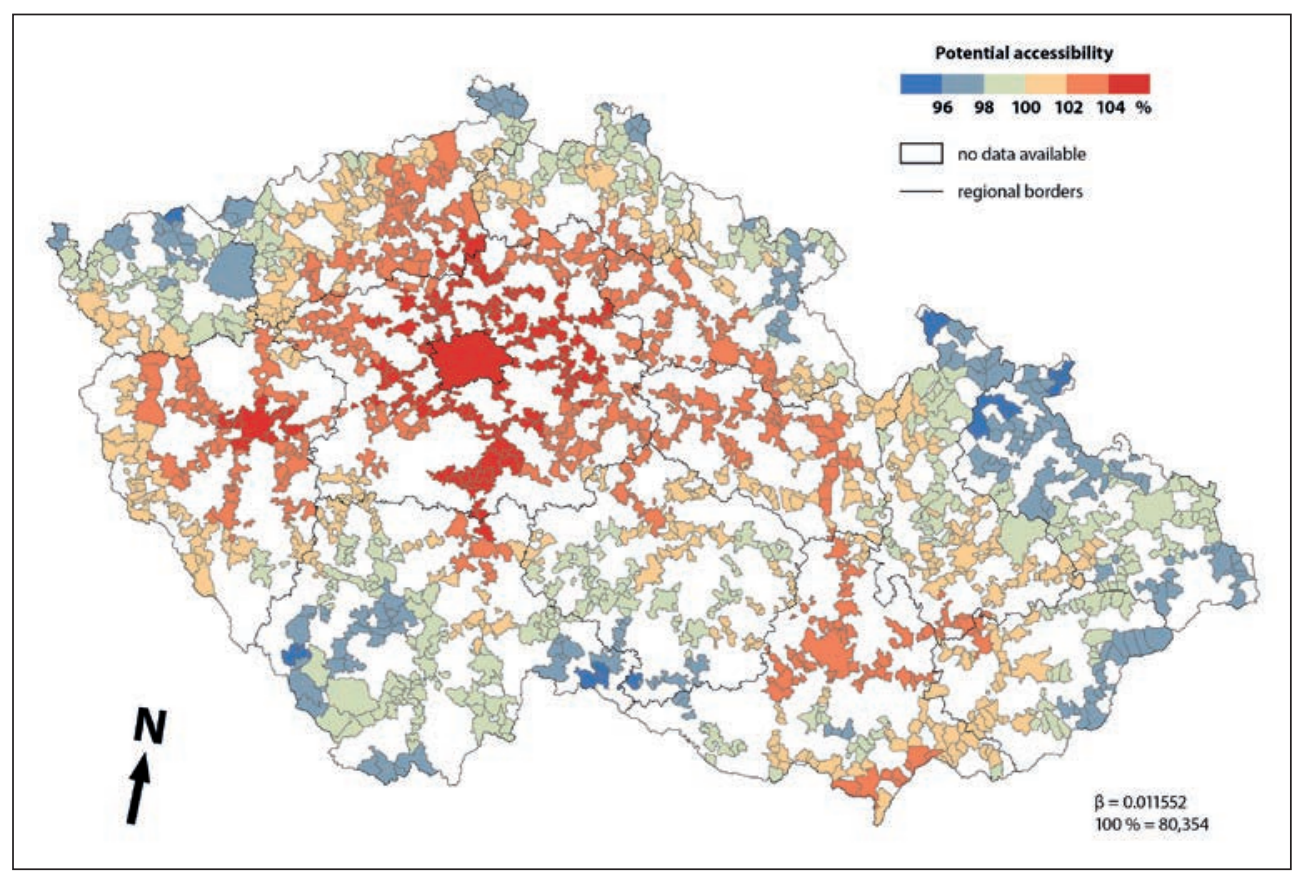

Fig. 8 Potential accessibility of municipalities in Czechia after the construction of HSR in the southern variant (long-distance model). Source: accessibility analysis, authors' calculation

means an increase of potential by $1.87 \%$. For the southern variant, the change from $135,515,582.28$ to $137,658,182.57$ represents a $1.58 \%$ increase in potential. In terms of changing the total potential accessibility, the eastern RS1 route appears to be the more advantageous option again. But, as can be seen from Figures 5 and 6 , from the regional benefits point of view, the southern variant of the long-distance model shows a significant increase in the number of municipalities with above-average potential accessibility than the eastern variant (65\% of municipalities with an above-average potential value in the eastern variant, $73 \%$ of the municipalities in the southern variant). From this point of view, on the contrary, the southern variant of the RS1 routing seems to be more advantageous, which, moreover, promotes the accessibility of the relatively remote South Bohemia with its long-term undersized transport infrastructure. 
Tab. 4 Value of potential accessibility of regional cities and its change (long-distance model).

\begin{tabular}{|c|c|c|c|c|c|}
\hline City & $\begin{array}{c}\text { Potential } \\
\text { accessibility - } \\
\text { long-distance model } \\
\text { (null variant) }\end{array}$ & $\begin{array}{c}\text { Potential } \\
\text { accessibility - long- } \\
\text { distance model (RS } \\
1 \text { eastern variant) }\end{array}$ & $\begin{array}{c}\text { Change of } \\
\text { potential } \\
\text { eastern/null }\end{array}$ & $\begin{array}{c}\text { Potential } \\
\text { accessibility - long- } \\
\text { distance model (RS } \\
1 \text { south variant) }\end{array}$ & $\begin{array}{c}\text { Change of } \\
\text { potential } \\
\text { southern/null }\end{array}$ \\
\hline Prague & $82,849.16$ & $83,531.72$ & $+0.82 \%$ & $83,448.19$ & $+0.72 \%$ \\
\hline Pilsen & $82,384.74$ & $83,499.54$ & $+1.35 \%$ & $83,458.79$ & $+1.30 \%$ \\
\hline Karlovy Vary & $80,992.00$ & $81,826.30$ & $+1.03 \%$ & $81,823.25$ & $+1.02 \%$ \\
\hline České Budějovice & $81,141.20$ & $82,200.67$ & $+1.30 \%$ & $83,202.32$ & $+2.54 \%$ \\
\hline Ústí nad Labem & $82,030.83$ & $82,965.85$ & $+1.13 \%$ & $82,824.82$ & $+0.97 \%$ \\
\hline Liberec & $81,357.02$ & $82,390.52$ & $+1.27 \%$ & $82,241.51$ & $+1.09 \%$ \\
\hline Hradec Králové & $82,011.54$ & $83,781.26$ & $+2.15 \%$ & $82,848.37$ & $+1.02 \%$ \\
\hline Pardubice & $82,269.64$ & $83,891.28$ & $+1.97 \%$ & $83,139.10$ & $+1.06 \%$ \\
\hline Jihlava & $81,404.25$ & $83,144.76$ & $+2.14 \%$ & $83,231.78$ & $+2.24 \%$ \\
\hline Brno & $82,298.58$ & $83,635.18$ & $+1.62 \%$ & $83,471.39$ & $+1.43 \%$ \\
\hline Zlín & $81,475.80$ & $83,281.12$ & $+2.21 \%$ & $83,151.27$ & $+2.06 \%$ \\
\hline Olomouc & $81,438.17$ & $83,289.95$ & $+2.27 \%$ & $83,213.01$ & $+2.18 \%$ \\
\hline Ostrava & $80,312.55$ & $81,442.02$ & $+1.41 \%$ & $81,339.98$ & $+1.28 \%$ \\
\hline
\end{tabular}

Source: accessibility analysis, authors' calculation

\section{Discussion and conclusion}

The aim of this article was to present the use of potential accessibility models in decision-making on tracing the high-speed rail infrastructure. On the example of so-called Rapid connections planned in Czechia, the possibilities of different calibration of the given analysis were introduced. The analyses of potential accessibility were always carried out for all municipalities in Czechia that are serviced by rail transport. At the same time, different routing of HSR from Prague to Brno in the Central Bohemian Region (RS1 eastern and southern variant) was assessed. Both levels of analysis compared both variants of routing in terms of the potential accessibility of all municipalities in the railway network. At the same time, the so-called regional and long-distance model were considered for both variants, which take into account the manner of servicing the entire territory.

Globally, accessibility profit was maximized at all major settlement centers in all 4 calculation variants in the future. Comparing the results from the individual service models, it became clear that in any case, profit was maximized in all district towns and lower-order centers. However, there was a greater gain for the eastern variant of RS1, as it will serve the relatively highly populated area of eastern Bohemia, and the cities of Pardubice and Hradec Králové are better located in the transport network than the eccentrically situated České Budějovice. However, in the calculations of the long-distance model (which is more significant from the HSR point of view, as it will enable the connection of regional cities to the backbone system of territorial service) the southern variant seems to be more advantageous $(73 \%$ of municipalities with above-average potential over the "null variant" without HSR).
Furthermore, a significant geographical aspect is evident where the peripheral areas of Czechia (such as Karlovy Vary Region, Zlín Region, etc.) get the most out of the whole system of Rapid Connections. It is also important to mention that when assessing highspeed rail, the main criterion should be the results from the long-distance model, as high-speed rails are built mainly because of connecting remote areas to major centers and also because of the connection of Czechia to the neighboring countries (although in our country mixed operation also for conventional trains that would serve micro-regional service is assumed).

With regard to the fact that these analyses involve modeling in the GIS environment and the results are partially distorted (they do not include the waiting time of the train at the station, the time for transfer, etc.), it is important to also consider the reality of railway transport in Czechia. South Bohemia is today poorly connected in terms of capacity transport and modernization of the so-called 3rd transit corridor counts on connection to HSR near Benešov. South Bohemia is also currently missing a motorway connection (D3 across the Central Region is difficult to negotiate). This fact, together with the results of all models of accessibility then speaks for the routing of the RS1 southern variant around towns of Benešov and Vlašim.

According to the literature discussed and the results of this research, the change in regional accessibility is the most significant territorial impact of high-speed rail. It manifests itself in various spheres of human activity - from spatial changes of population distribution, support and, development of regional/local economy to changes in tourism attractiveness. When assessing the appropriate routing of traffic structures not only in Czechia, it is therefore important to 
address this topic in detail. However, when assessing multiple options, accessibility models (whether time or potential) are not the only scientific tools and the economic and environmental impacts of each solution must always be assessed as well.

Potential accessibility has proved to be a suitable tool for assessing changes induced by the construction of new high-speed infrastructure, since it not only takes into account the change in time but also the importance of settlements and their mutual location. The effects of regional and long-distance transport can be appropriately simulated by calibrating the beta time coefficient. Potential accessibility is therefore a challenge predominantly in transport planning and should be given more attention in the preparation of strategic documents and in the preparation of CBA analyzes, as these mostly work with simple time accessibility, respectively with time savings. The potential accessibility can better describe the changes that the construction of new infrastructure will bring.

\section{Acknowledgements}

This article is the output of the project called "New Mobility - High-Speed Transport Systems and Transport-Related Human Behaviour", Reg. No. CZ.02.1. $01 / 0.0 / 0.0 / 16 \_026 / 0008430$, co-financed by the "Operational Programme Research, Development and Education".

\section{References}

Clark, A. N. (1990): The Penguin Dictionary of Geography, Harmondsworth.

Gutiérrez, J. (2001): Location, economic potential and daily accessibility: an analysis of the accessibility impact of the high-speed line Madrid-Barcelona-French border. Journal of Transport Geography 9(4), 229-241, https://doi.org/10.1016/S0966-6923(01)00017-5.

Guy, C. M. (1983): The Assessment of Access to Local Shopping Opportunities: a Comparison of Accessibility
Measure. Environment and Planning B: Planning and Design 10(2), 219-238, https://doi.org/10.1068 /b100219.

Haynes, R., Lovett, A., Sünnenberg, G. (2003): Potential Accessibility, Travel Time, and Consumer Choice: Geographical Variations in General Medical Practice Registrations in Eastern England. Environment and Planning A: Economy and Space 35(10), 1733-1750, https://doi.org/10.1068/a35165.

Hudeček, T., Churaň, R., Kufner, J. (2011): Dostupnost Prahy při využití silniční dopravy v období 1920-2020. Geografie 116(3), 317-334, https://doi.org/10.37040 /geografie2011116030317.

Hall, P., Chen, C. L. (2012): The wider spatial-economic impacts of high-speed trains: a comparative case study of Manchester and Lille sub-regions. Journal of Transport Geography 24, 89-110, https://doi.org/10.1016 /j.jtrangeo.2011.09.002.

Maier, K. et al. (2007): Dopravní dostupnost funkčních městských regionů a urbanizovaných zón v České republice. Urbanizmus a územní rozvoj 3, 75-80.

Marada, M., Květoň, V. (2016): Transport Supply and Demand Changes in Relation to Unemployment: Empirical Evidence from the Czech Republic in a Time of Crisis. Journal of Economic and Human Geography 107(5), 611-627, https://doi.org/10.1111/tesg .12186.

Rich, D. C. (1980): Potential Models in Human Geography. Concepts and Techniques in Modern Geography, Norwich.

Salze, P. et al. (2011): Estimating Spatial Accessibility to Facilities on the Regional Scale: an Extended Commuting-Based Interaction Potential Model. International Journal of Health Geographics 10, 1-17, https://doi.org/10.1186/1476-072X-10-2.

Sands, B. D. (1993): The Development Effects of High-Speed Rail Stations and Implications for California. University of California in Berkeley, Berkeley.

Taylor, Z. (1997): Dostepność miejsc pracy, nauki i uslug w obszarach wiejskich jako przedmiot badań geografii spoleczno-ekonomicznej - próba analizy krytycznej. Przeglad geograficzny 69, 261-283.

van Wee, B. et al. (2001): Accessibility measures with competition. Journal of Transport Geography 9(3), 199-208, https://doi.org/10.1016/S0966-6923 (01)00010-2. 